\title{
Maize hybrid stability in environments under water restriction using mixed models and factor analysis
}

A.O. Santos ${ }^{1}$, J.J. Nuvunga ${ }^{2}$, C.P. Silva ${ }^{2}$, L.P.M. Pires ${ }^{1}$, R.G. Von Pinho ${ }^{1}$, L.J.M. Guimarães ${ }^{3}$ and M. Balestre ${ }^{2}$

${ }^{1}$ Departamento de Agricultura, Universidade Federal de Lavras, Lavras, MG, Brasil

${ }^{2}$ Departamento de Estatística, Universidade Federal de Lavras, Lavras, MG, Brasil

${ }^{3}$ Embrapa Milho e Sorgo, Sete Lagoas, MG, Brasil

Corresponding author: M. Balestre

E-mail: marciobalestre@des.ufla.br

Genet. Mol. Res. 16 (2): gmr16029672

Received March 17, 2017

Accepted May 5, 2017

Published June 29, 2017

DOI http://dx.doi.org/10.4238/gmr16029672

Copyright $(2017$ The Authors. This is an open-access article distributed under the terms of the Creative Commons Attribution ShareAlike (CC BY-SA) 4.0 License.

\begin{abstract}
In several crops, the water deficit is perhaps the main limiting factor in the search for high yields. The objective of this study was to evaluate the phenotypic stability of maize hybrids in environments with and without water restriction using the analytical factor (AF) approach. We evaluated 171 maize hybrids in 14 environments, divided into environments with (A1, A2, A3, A4, A5, A6, and A7) and without (A8, A9, A10, A11, A12, A13, and A14) water restriction, over a period of 7 years. Each year, 36 hybrids were evaluated. A square lattice design $(6 \times 6)$ was used, with common treatments between years. The characteristics of grain yield (GY), male flowering (MF) and female flowering $(\mathrm{FF})$, plant height $(\mathrm{PH})$, and ear height $(\mathrm{EH})$ were evaluated. Phenotypic adaptability and stability of the hybrids were also verified. Hybrids G66, G99, G86, and G26 were the most stable and showed
\end{abstract}


potential for use in environments with and without water restriction. The AF models showed to be useful for evaluating hybrids over many years, allowing selection of better hybrids with adaptability, specific and general stability, and correlation of hybrids with their production components, in addition to allowing identification of mega-environments that permit stability in the response of the adapted hybrids.

Key words: Zea mays; Water stress; Stability; Factor analysis; Multi-environments

\section{INTRODUCTION}

In several crops, the water deficit is perhaps the main limiting factor in the search for high grain yields (GY). Therefore, the use of genotypes tolerant to water deficit is an effective strategy for increasing yield and reducing risks for production in areas subject to periods of water restriction.

However, tolerance to water deficit in crops is probably the most difficult trait to identify with precision. Given the low heritability of the trait of GY under water deficit conditions, genetic progress is difficult to achieve through direct selection. Secondary characteristics are those correlated with the main traits, such as GY, providing an indirect measure of plant performance in the evaluation environments. An ideal secondary characteristic must be genetically correlated with GY and present high genetic variability, high heritability, and be stable throughout the period of evaluation. Besides, it cannot be associated with any factor of yield loss under conditions without stress, thus allowing good perspectives of gain from selection (Edmeades et al., 1999; Lafitte et al., 2003).

For this reason, evaluation of characteristics such as the interval between male and female flowering, plant height, prolificity, and leaf senescence, among others, have led to success in obtaining maize hybrids with greater tolerance to water deficit.

Nevertheless, an inherent challenge to selection for GY is that it is a highly complex characteristic that is highly influenced by the environment through the genotype $\mathrm{x}$ environment (GxE) interaction (Lopes et al., 2011). In this regard, it is important to emphasize that in the literature it is frequently reported that a considerable part of this dynamic may also be attributed to the genotype $\mathrm{x}$ crop year interaction (Peixouto et al., 2016). Therefore, it is important to use statistical analysis resources that allow a better understanding of how these interactions affect GY of the different maize hybrids.

In this respect, Piepho (1998) proposed a factor analytic multiplicative mixed model that considers random effects of genotypes and the GxE interaction. In the same context, Smith et al. (2001) proposed a general class of analytic factor (AF) models that encompassed the approach of Piepho (1998) and included spatial errors for each trial based on Figueiredo et al. (2014). In this way, the authors sought to develop models that could provide considerations by data from various evaluation environments.

The AF methodology can be used effectively in the study of the GxE interaction in maize breeding programs. In this regard, Nuvunga et al. (2015) used this methodology in evaluation of three levels of data imbalance, reaching up to $50 \%$, and found that the $\mathrm{AF}$ methodology is robust in data analysis in multi-environments, including situations in which the genotypes are not evaluated in all the environments and/or years. Furthermore, the authors

Genetics and Molecular Research 16 (2): gmr16029672 
concluded that under the mixed model approach, the AF methodology is effective at different levels of unbalanced data, with correlation values ranging from medium to high, depending on the established level of loss.

The use of the AF methodology related to studies of the GxE interaction in maize hybrids subjected to environments with water deficit is still not very common, but it is a promising tool.

Thus, the aim of this study was to evaluate the stability of maize hybrids in different environments through the AF approach.

\section{MATERIAL AND METHODS}

\section{Setting up and conducting trials}

Trials were set up in an area of the Experimental Station of the Embrapa Milho e Sorgo, in Nova Porteirinha, in the north of the State of Minas Gerais, Brazil, from 2007 to 2013. The local climate is tropical, mesothermal, and nearly megathermal, due to the altitude, with low moisture and semiarid characteristics and intermittent rains, leading to long drought periods.

The trials were set up and carried out in a period of low possibility of rainfall in the region to ensure the control of water application through irrigation. Thus, crops were sown in May and June, depending on the year considered, under a drip irrigation system. Water stress was imposed through suspending irrigation in the plots of environments with water restriction from the years 2007 to 2013 (A1, A2, A3, A4, A5, A6, and A7, respectively) at 45 days after sowing, then remaining up to harvest. In the environments without water restriction from the years 2007 to 2013 (A8, A9, A10, A11, A12, A13, and A14, respectively), the plants were regularly irrigated up to the R3 stage, maintaining field capacity of the soil.

A $6 \times$ 6-square lattice experimental design was used, with two replications, in environments A1, A2, A8, and A9 and four replications in the other environments. Plots consisted of a 4-mlength row, with a between-row spacing of $0.8 \mathrm{~m}$, and the useful area of the plot was $3.2 \mathrm{~m}^{2}$. The final plant population was 60 thousand plants/ha.

In fertilization at planting, $400 \mathrm{~kg} / \mathrm{ha}$ of the fertilizer formulation NPK 8-28-16 was used. In topdressing, $200 \mathrm{~kg} / \mathrm{ha}$ urea was used when the plants were in the three fully expanded leaf (V3) and six fully expanded leaf (V6) stages.

The other crop treatments were carried out according to crop needs so as to obtain the greatest yield of the hybrids evaluated.

We evaluated 171 maize hybrids in the value for cultivation and use (VCU) phase, obtained from the plant breeding program of Embrapa Milho e Sorgo, together with commercial hybrids from different companies, used as controls (Table S1).

\section{Characteristics evaluated}

The following agronomic characteristics were evaluated:

Ear height (EH): mean height of the ear in five representative plants of the plot, obtained by measuring the distance from the soil to the point of connection of the upper ear of the plant to the stalk.

Plant height (PH): mean height of five representative plants of the plot, obtained by measuring the distance from the soil to the ligule of the flag leaf.

Genetics and Molecular Research 16 (2): gmr16029672 
Male flowering (MF): values about days after sowing, at which $50 \%$ of the plants of the plot had tassels releasing pollen.

Female flowering (FF): values about days after sowing, at which $50 \%$ of the plants of the plot had visible style-stigmas in the ears.

GY: obtained in grams per plot and later transformed into $\mathrm{kg} / \mathrm{ha}$, at $13 \%$ moisture, through the equation:

$$
\mathrm{GY}=\mathrm{GW} \times\left(\frac{10000}{\mathrm{UA}}\right) \times\left[\frac{(100-\mathrm{GM})}{87}\right]
$$

where GY: grain yield in $\mathrm{kg} / \mathrm{ha}$, at 13\% moisture; GW: grain weight in $\mathrm{kg}$ per plot; UA: useful area of the plot, in $\mathrm{m}^{2}$; GM: grain moisture at the time of harvest, in $\%$.

\section{Data analysis}

Analysis was carried out in two steps: the first used the mixed model approach to fit the fixed effects (of environments confounded with locations), random effects (of genotypes), and the residual variance matrix using the REML/BLUP procedure through the EM algorithm, according to Nuvunga et al. (2015) and proposed by Patterson and Thompson (1971).

The second step consisted of fitting the model of factor analysis to obtain the EBLUP of the factor scores and loading related to environments. These measures fitted in the second step serve as parameters to evaluate the adaptability and stability (Stefanova and Buirchell, 2010) of the genotypes evaluated for recommendations (Smith et al., 2015).

\section{Description of the model for analysis in the first step}

A combined analysis was carried out based on the dataset considering the following linear mixed model:

$$
y=X \beta+Z u+e
$$

(Equation 2)

where $\mathbf{y}$ is the vector $(n \times 1)$ attributed to all $n$ observations of all environments; $\beta_{(\mathrm{tx})}$ is the fixed effect vector associated with the design matrix $\mathrm{X}_{(\mathrm{n} \times \mathrm{t})} ; \mathrm{u}_{(\mathrm{b} \times 1)}$ is the random effect vector associated with the design matrix $\mathrm{Z}_{(\mathrm{n} \times \mathrm{b})}$; and $\mathrm{e}_{(\mathrm{n} \times 1)}$ is the residual effect of the error vector.

It was assumed that $e \sim N(0, R)$ and $u \sim N(0, G)$ are independent and

$$
\left(\begin{array}{l}
\varepsilon \\
u
\end{array}\right) \sim N\left(0,\left(\begin{array}{cc}
I_{n} \otimes R & 0 \\
0 & I_{n} \otimes G
\end{array}\right)\right) \quad \text { (Equation 3) }
$$

It was assumed that the phenotypic data distribution is given by $y \sim N\left(X \beta, Z G Z^{T}+R\right)$, where $\Sigma=\mathrm{ZGZ}^{\mathrm{T}}+\mathrm{R}$.

The analysis implies a mixed model that includes the main effects of environments and genotypes (at least one set of main effects should be considered as random) and random to the GxE interaction.

Genetics and Molecular Research 16 (2): gmr16029672 
Considering the premises of the Equation 2 and making:

$$
C=\left[\begin{array}{cc}
X^{\prime} R^{-1} X & X^{\prime} R^{-1} Z \\
Z^{\prime} R^{-1} X & Z^{\prime} R^{-1} Z+\Sigma^{-1}
\end{array}\right]=\left[\begin{array}{cc}
C_{11} & C_{12} \\
C_{21} & C_{22}
\end{array}\right]
$$

the variance components are estimated as:

$$
\begin{gathered}
\tilde{\sigma}_{e_{i j}}=\left\{e_{i}^{T} e_{j}+\operatorname{tr}\left(\left[K C^{-1} K^{t}\right]_{i j}\right)\right\} / n^{*} \\
\tilde{\sigma}_{e_{i j}}=\left\{\begin{array}{l}
\sigma_{e_{k}}^{2} \text { if } \mathrm{i}=\mathrm{j} \\
\sigma_{e_{i j}} \text { if opposite }
\end{array}\right.
\end{gathered}
$$

where $K=\{X, Z\}$ and the trace depends on the submatrix related to and $j$, with $n^{*}$ being the length of the vector $\{j, i\}$.

\section{Second step of analysis}

Factor analysis in restricted likelihood can be implemented given the (co)variance matrices $\Sigma$ and R obtained in step 1. For that reason, it was assumed that $\Sigma$ could be represented by an AF structure, that is $\left(\mathrm{LL}^{\mathrm{T}}+\Psi\right)$ and that the BLUPs could be represented by common factors in the form $(u=L f+\delta)$. This transformation was carried out in the linear mixed model (Equation 2), and it was found that:

$$
y=X \beta+Z[L f+\delta]+e
$$

Where $\mathrm{f}$ represents the vectors of the factor scores related to missing information (EBLUPs); $\delta$ is the specific variance; $\mathrm{L}$ represents the factor loading matrix, and $\mathrm{X}$ and $\mathrm{Z}$ are the design matrices. Also, it was assumed that

$$
f \sim N(0, I), \delta \sim N(0, \Psi), \text { and } e \sim N(0, R)
$$

\section{Estimation, prediction, and fitting of the model}

Considering the model of the analysis presented in Equation 2, the best linear unbiased estimates (BLUEs) for the fixed effects and the best linear unbiased predictors (BLUPs) for the random effects were, respectively:

$$
\hat{\beta}=\left(X^{T} R^{-1} X\right)^{-1} X^{T} R^{-1} y
$$

and

$$
\hat{u}=G Z H^{-1}\left(X^{T} R^{-1} X\right)^{-1}(y-X \beta)
$$

Genetics and Molecular Research 16 (2): gmr16029672 
The second phase of fitting the model consisted of fitting the AF model for calculation of the parameters $\mathrm{L}$ and $\Psi$ of the AF model, and, consequently, for calculation of the $\mathrm{f}$ (BLUPs) scores of genotypes (Smith et al., 2001; Nuvunga et al., 2015).

Assuming $\mathrm{W}=\mathrm{ZL}$, the estimates of the parameters were:

$$
\begin{gathered}
\hat{f}=\left(W^{T} R^{-1} W+I\right)^{-1} W^{T} R^{-1}(y-X b-Z \delta) \\
\hat{\delta}=\left(Z^{T} R^{-1} Z+\Psi^{-1} \otimes I\right)^{-1} Z^{T} R^{-1}(y-X b-W f)
\end{gathered}
$$

Nuvunga et al. (2015) highlight that the loading matrix (L) is not unique and the imposition of restriction is necessary to make it unique, recommending a Varimax rotation that we adopted in this study.

Due to a similar interpretation of the AF and GGE-Biplot models, the factor scores and the loads were represented in a biplot for selection of genotypes in stable environments, delimitation of mega-environments, and identification of the "which-won-where" pattern.

All analyses were carried out using the R statistical software (R Core Team, 2013).

\section{RESULTS AND DISCUSSION}

The climate data observed during the period in which the experiments were evaluated in the field were considered suitable for our study (Figure 1) since accumulated rainfall was extremely low, corroborating the results found by Albuquerque et al. (2006) who, after a detailed study of the soil and climate conditions throughout the various years of the experimental station of Nova Porteirinha, found that the location has a highly pronounced period of water deficit, making it a suitable location for implementation of studies for verification of tolerance to water deficit. The rainfall registered in May 2012 of approximately $42 \mathrm{~mm}$ did not affect the imposition of stress conditions since at that period the trials were in the irrigation phase.

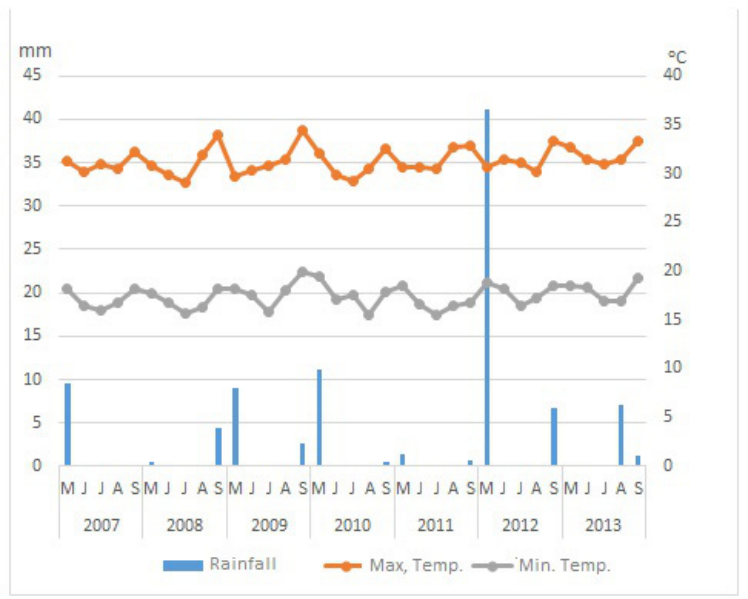

Figure 1. Rainfall, mean maximum temperature (Max. Temp.) and mean minimum temperature (Min. Temp.) in the months of May (M), June (J), July (J), August (A), and September (S) in the different years of hybrid evaluation. UFLA, Lavras, MG, Brazil, 2016. 
The identification of environments that have long periods of drought has been one of the big challenges in evaluation of maize hybrids tolerant to water deficit since the occurrence of rains during the stage of evaluation can lead to inaccurate conclusions, reducing the effectiveness of selection. In this respect, some studies have highlighted the importance of ideal environments for greater efficiency in evaluation and selection of maize hybrids with tolerance to water deficit (Campos et al., 2006; Cooper et al., 2014).

Resende and Duarte (2007) proposed an approach for evaluating the quality of experiments, emphasizing the need of using methods of estimation/prediction of the genotypic values that utilize shrinkage on the phenotypic mean of the cultivar, and they established intervals for judgment of selective accuracy as a measure of experimental precision. Thus, it could be verified that in this study the experiments had good precision since the accuracy estimates had values of high magnitude for the characteristics evaluated (Table 1).

Table 1. Genotypic mean (M.) and selective accuracy (Ac.) for the traits related to ear height (EH), plant height $(\mathrm{PH})$, male flowering (MF), female flowering (FF), and grain yield (GY) in $\mathrm{t} /$ ha for the 14 environments (Env.) of evaluation (UFLA, Lavras, MG, Brazil, 2016).

\begin{tabular}{|c|c|c|c|c|c|c|c|c|c|c|}
\hline \multirow[t]{2}{*}{ Env. } & \multicolumn{2}{|c|}{ EH } & \multicolumn{2}{|c|}{ PH } & \multicolumn{2}{|c|}{ MF } & \multicolumn{2}{|c|}{ FF } & \multicolumn{2}{|c|}{ GY } \\
\hline & M. & Ac. & M. & Ac. & M. & Ac. & M. & Ac. & M. & Ac. \\
\hline Al & 1.15 & 81.23 & 1.99 & 85.72 & 60 & 90.21 & 59 & 92.33 & 4.89 & 80.85 \\
\hline A2 & 1.00 & 83.15 & 1.86 & 81.88 & 68 & 88.76 & 67 & 91.30 & 4.20 & 79.21 \\
\hline A3 & 1.04 & 81.19 & 2.01 & 79.93 & 64 & 89.54 & 62 & 89.08 & 4.26 & 84.12 \\
\hline A4 & 1.21 & 84.43 & 2.30 & 82.41 & 67 & 92.32 & 65 & 93.56 & 4.56 & 77.34 \\
\hline A5 & 1.42 & 82.32 & 2.49 & 85.31 & 66 & 91.04 & 65 & 90.12 & 5.20 & 80.05 \\
\hline A6 & 1.03 & 79.58 & 2.06 & 78.22 & 66 & 90.92 & 64 & 87.25 & 3.53 & 78.18 \\
\hline A7 & 1.23 & 82.45 & 2.27 & 85.54 & 64 & 92.66 & 64 & 91.63 & 4.95 & 81.24 \\
\hline A8 & 1.19 & 83.12 & 2.13 & 82.13 & 60 & 89.31 & 60 & 90.20 & 6.54 & 80.66 \\
\hline A9 & 1.07 & 86.65 & 2.16 & 88.21 & 64 & 86.95 & 64 & 88.92 & 5.63 & 79.16 \\
\hline $\mathrm{A} 10$ & 0.99 & 86.21 & 2.06 & 84.99 & 64 & 90.02 & 64 & 91.09 & 8.85 & 83.52 \\
\hline A11 & 1.34 & 83.67 & 2.37 & 80.31 & 68 & 89.27 & 67 & 89.34 & 8.13 & 79.31 \\
\hline A12 & 1.42 & 87.96 & 2.48 & 88.46 & 65 & 93.15 & 64 & 94.47 & 8.54 & 85.12 \\
\hline A13 & 1.22 & 82.31 & 2.33 & 82.39 & 61 & 88.78 & 61 & 91.81 & 7.51 & 82.95 \\
\hline $\mathrm{A} 14$ & 1.22 & 87.36 & 2.30 & 83.22 & 64 & 90.73 & 64 & 90.07 & 8.20 & 80.07 \\
\hline
\end{tabular}

Smith et al. (2015) showed the utility of the AF models for analysis of VCU data, and although this approach is quite widespread in Australia and the United Kingdom for analysis of such data, this methodology could be more highly used in other locations.

Considering the overall means observed, for $\mathrm{EH}$, they ranged from 0.99 (A10) to $1.42 \mathrm{~m}$ (A5 and A12); forPH, from 1.86 (A2) to 2.49m (A5); for MF, from 60 (A1) to 68 days (A2, A11); for FF, from 59 (A1) to 67 days (A2, A11); and for GY, from 3.53 (A6) to 8.85 t/ha (A10).

Reductions in the mean values in the environments with water restriction were observed for the characteristics $\mathrm{EH}, \mathrm{PH}$, and GY, related to the pairs of environments without water restriction. For $\mathrm{EH}$, the reduction ranged from 1.77 to $6.24 \%$; for $\mathrm{PH}$, there was a reduction from 5.40 to $6.75 \%$; and for GY, the reduction observed ranged from 36.19 to 48.14\%. Bänziger et al. (2000) found that for the environments of evaluation of maize hybrids to be contrasting and, therefore, ideal for this type of study, reduction in the GY should be between 40 and $60 \%$, corroborating the results observed in this study.

Graph analysis through biplots has been used for interpretation of results in studies of evaluation of maize hybrids for tolerance to water deficit. In the study of Stefanova and Buirchell (2010), the correlation between the first-factor score and the EBLUPs of the genotypes was 0.99 , and the interpretation of the environments in the AF model is similar to the interpretation of GGE biplots.

Genetics and Molecular Research 16 (2): gmr16029672 
In the analysis of graphs of AF models, stability can be described by the scores of Factor 2. Thus, productive and stable genotypes should have high scores for Factor 1, but values nearer to zero for Factor 2, which suggests that these scores correspond to genotypes that are not specific for environment groups (Nuvunga et al., 2015).

For the EH characteristic, it was observed that the A8 environment contributed less to the GxE interaction (Figure 2). In environments A2, A5, A7, A10, and A13, it was possible to group the greatest number of hybrids, indicating that this macro-environment allowed more general adaptation to the group of evaluated hybrids. The hybrid G98 showed good adaptability in environments A6 and A14.

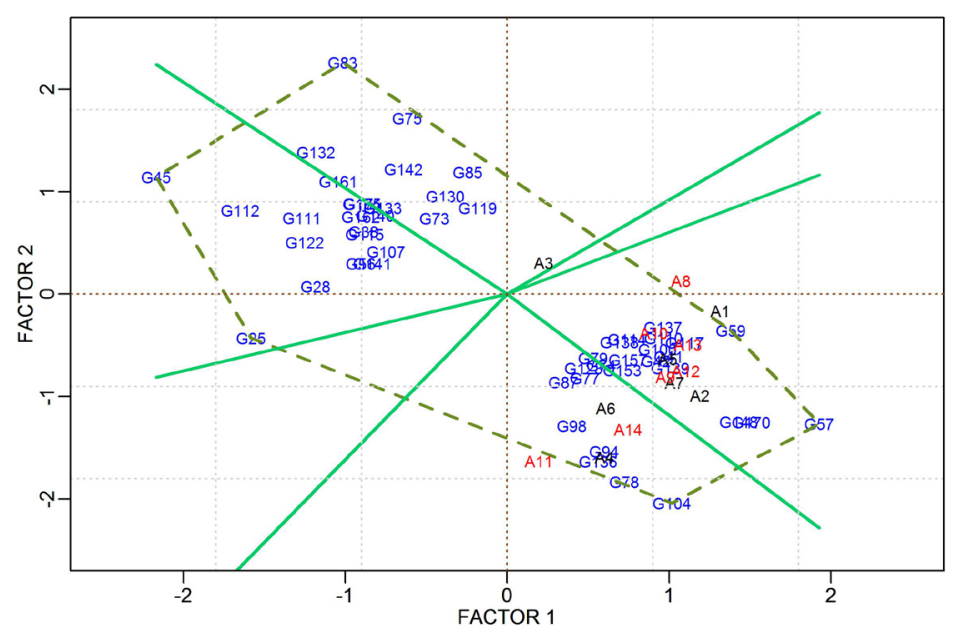

Figure 2. Factor loading and scores obtained in multi-environment analysis considering the environments with (A1, A2, A3, A4, A5, A6, and A7) and without (A8, A9, A10, A11, A12, A13, and A14) water restriction for 15\% of the hybrids with highest and lowest EH according to Factor 1. UFLA, Lavras, MG, Brazil, 2016.

Thus, for Factor 2, the genotypes that are more distant from the origin are those that most contribute to the GxE interaction; that is, they show a specific response to a group of environments (Nuvunga et al., 2015).

For the PH characteristic, it was found that environments A2 and A5 contributed less to the GxE interaction (Figure 3). In contrast, the A4 environment was the one that most contributed to the interaction. It was also observed that for $\mathrm{PH}$, there was a concentration of the best values in environments A1, A2, A6, andA12. In environments A2, A5, A7, A9, and A14, the hybrids that stood out were G99, G100, and G102.

$\mathrm{PH}$ is an important characteristic and should be evaluated in studies aiming at tolerance to water deficit since taller plants tend to have higher rates of leaning over and breakage. Besides, reduction in plant growth was positively correlated with the level of stress applied (Bai et al., 2006). Thus, the search for maize hybrids with lower PH in environments with low water availability is recommended (Hao et al., 2011).

Another point to consider refers to the high correlation between $\mathrm{EH}$ and $\mathrm{PH}$ (Bänziger et al., 2000), and these characteristics coincided $57.69 \%$ in environments with water restriction and $53.84 \%$ in environments without water restriction.

Genetics and Molecular Research 16 (2): gmr16029672 


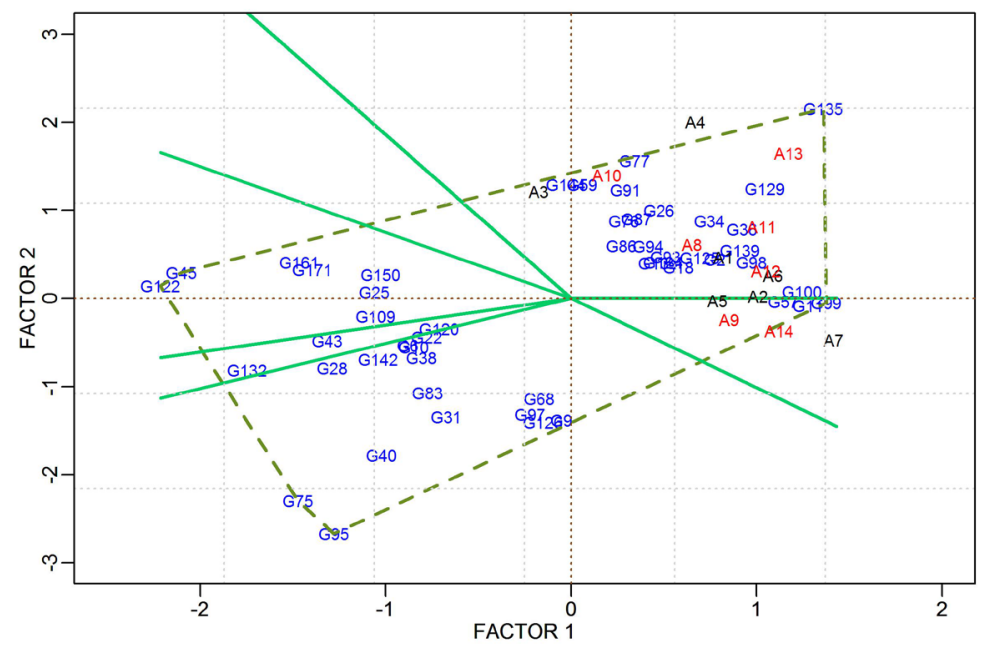

Figure 3. Factor loading and scores obtained in multi-environment analysis considering the environments with (A1, A2, A3, A4, A5, A6, and A7) and without (A8, A9, A10, A11, A12, A13, and A14) water restriction for 15\% of the hybrids with highest and lowest PH according to Factor 1. UFLA, Lavras, MG, Brazil, 2016.

For MF, hybrid G54 showed the greatest stability (Figure 4). Environments A3, A4, A10, and A11 showed a greater concentration of hybrids with lower values for MF. Hybrids G41 and G42 showed good adaptability to environments A1, A2, A8, and A9. Clustering of the A6 and A13 environments was observed. An important observation for this characteristic is that upon considering the clustering of environments, a similar result was seen as a function of year of evaluation. For example, environments A6 and A13 are regarding the year of evaluation 2012 and, in this respect, the hybrids had similar performance in the environments for this period.

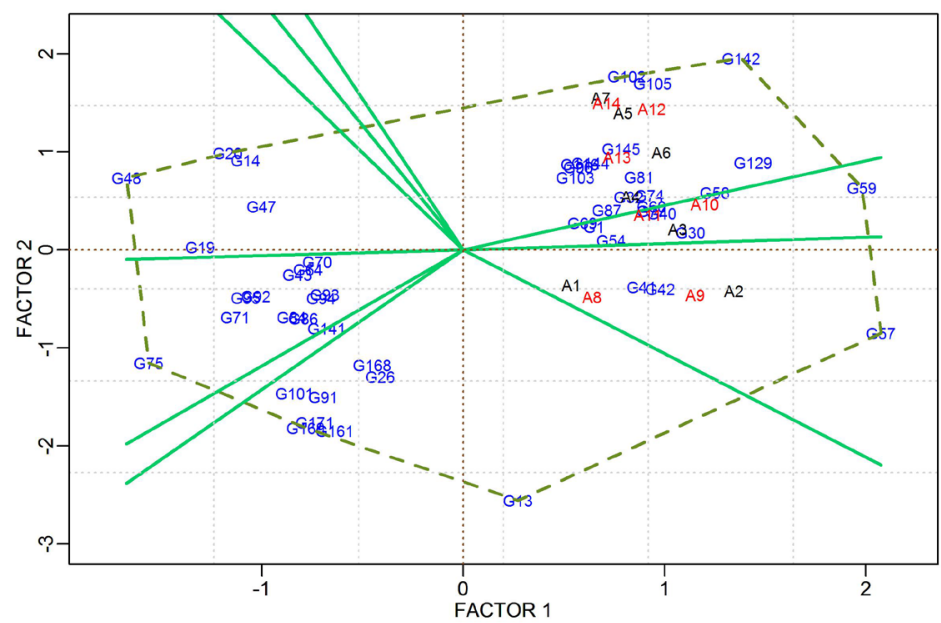

Figure 4. Factor loading and scores obtained in multi-environment analysis considering the environments with (A1, A2, A3, A4, A5, A6, and A7) and without (A8, A9, A10, A11, A12, A13, and A14) water restriction for 15\% of the hybrids with highest and lowest MF according to Factor 1. UFLA, Lavras, MG, Brazil, 2016.

Genetics and Molecular Research 16 (2): gmr16029672 
For the FF characteristic, hybrids G32, G57, G58, and G59 showed greater adaptability to environments A1, A2, A8, and A9. In environments A6 and A13, the best hybrids were G135, G153, and G162 (Figure 5).

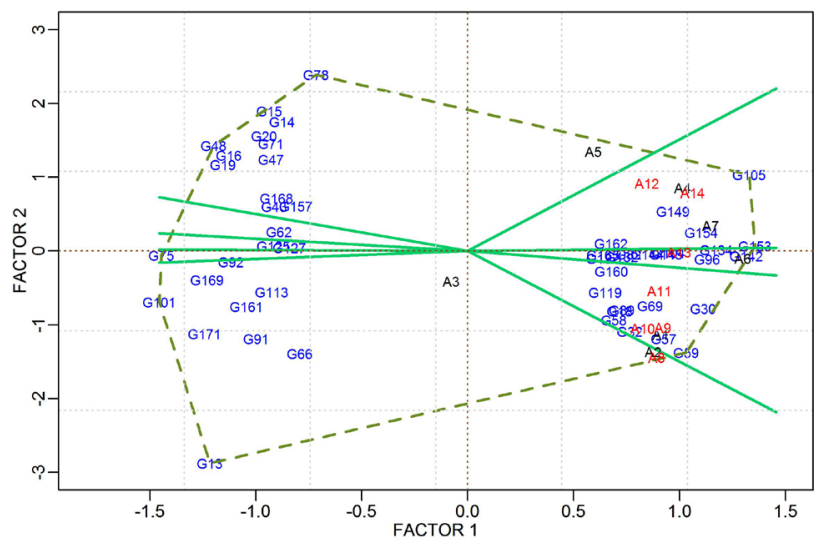

Figure 5. Factor loads and scores obtained in multi-environment analysis considering the environments with (A1, $\mathrm{A} 2, \mathrm{~A} 3, \mathrm{~A} 4, \mathrm{~A} 5, \mathrm{~A} 6$, and A7) and without (A8, A9, A10, A11, A12, A13, and A14) water restriction for 15\% of the hybrids with highest and lowest FF according to Factor 1. UFLA, Lavras, MG, Brazil, 2016.

For GY, the environments that least contributed to the GxE interaction were environments A1, A2, A7, and A8 (Figure 6). Of these, only A8 belongs to the group without water restriction, indicating that the environments with water restriction may allow more reliable evaluation of the genotype. In the A4 environment, hybrid G66 showed a high mean value for GY. Hybrids G42, G60, and G65 had good performance in environments A3, A11, and A12. For this characteristic, it has been reported that the GxE interaction is of the complex type, being highly influenced by the environment (Lopes et al., 2011). Furthermore, an allele associated with a determined gene or QTL has different effects depending on the environmental condition in which it is found (Chenu et al., 2009).

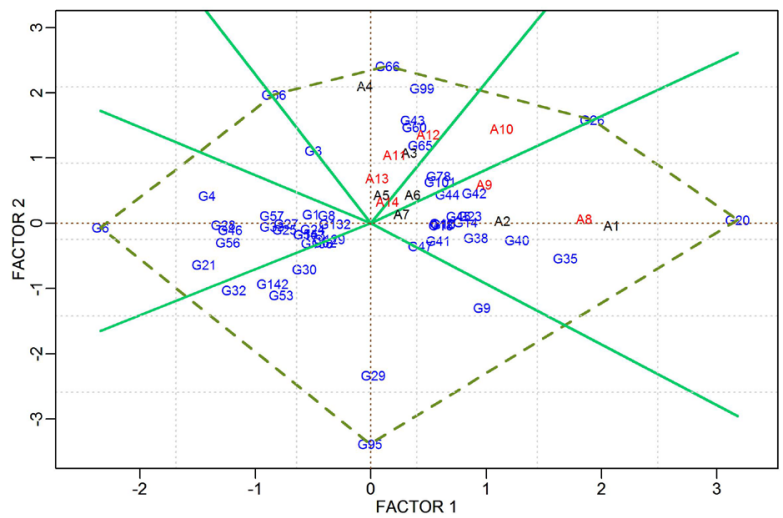

Figure 6. Factor loads and scores obtained in multi-environment analysis considering the environments with (A1, $\mathrm{A} 2, \mathrm{~A} 3, \mathrm{~A} 4, \mathrm{~A} 5, \mathrm{~A} 6$, and A7) and without (A8, A9, A10, A11, A12, A13, and A14) water restriction for 15\% of the hybrids with highest and lowest GY according to Factor 1. UFLA, Lavras, MG, Brazil, 2016.

Genetics and Molecular Research 16 (2): gmr16029672 
In general, there was a change in the ranking of the hybrids in environments with and without water restriction. The coincidence between the environments was $49.12 \%$ for the hybrids with highest GYand $41.87 \%$ for the hybrids with lowest GY. Hybrids G66, G99, G86, and G26 showed good stability and have the potential for use in environments with and without water restriction.

In maize plants under water deficit conditions, the decrease in GY is directly related to the duration and intensity of the stress period, as well as the stage of development of the plant in which this stress occurs. In this respect, greater reductions have been observed when water deficit occurs between the end of the vegetative stages up to reproductive stage 3 (R3), which may cause reductions of up to $100 \%$ (Chen et al., 2012). In this study, in all years, water restriction was imposed at 45 days after sowing, coinciding with the critical periods of water deficit for the maize plant, which allowed evaluation and discrimination of the hybrids.

Some studies have shown that the genotype by year interaction can be even greater than the genotype by location interaction (Assefa et al., 2012; Cooper et al., 2014). Thus, selection of maize hybrids should be based on evaluations of more than 1year, aiming at greater precision in identification of higher yielding hybrids. In this study, although not all the hybrids were evaluated consecutively over the 7 years, the information and estimates observed allowed reliable inferences regarding the performance of the hybrids.

The selection of maize hybrids tolerant to water deficit should be carried out in environments with and without water restriction (Cooper et al., 2014). That way, it is possible to evaluate the response of hybrids related to an environmental stimulus, allowing selection of hybrids with greater stability and that have good GY under conditions of water deficit and that also have good GY under non-stress conditions. Besides, in this system of evaluation, it is possible to carry out screening of the germplasm, eliminating lines or hybrids that do not have desirable characteristics, or even selecting hybrids tolerant to water deficit for agricultural use in regions that have similar environmental conditions. In this respect, Campos et al. (2006) and Chapman et al. (1997) highlighted that gain from selection for GY in environments with water deficit is low when selection is based on environments without water restriction.

When the main effects of the genotypes are included in the model, the first factor mainly reflects genotype performance and can be used for evaluation of genetic gain. Furthermore, if a two-factor model provides a reasonable fit and explains a large proportion of GxE interactions, after that, the second factor can be used to illustrate the stability of cultivars in the series of environments (Stefanova and Buirchell, 2010; Nuvunga et al., 2015).

The AF methodology used in this study allowed the evaluated hybrids to be discriminated, despite the high degree of unbalanced data, and allowed inferences to be made regarding their adaptability and stability. This is even more interesting when considering the situation of plant breeding programs in general, in which unbalanced data are common, as in the case of this study, which considers a series of data from VCU trials, set up over a series of years, in which better performing hybrids are retained for at least 2 years and the others substituted by new hybrids. Figueiredo et al. (2014) also found that the AF methodology can safely be used in studies of adaptability and stability in trials with a high degree of unbalanced data. Moreover, we can highlight the study of Smith et al. (2015) who emphasized the superiority of this methodology for evaluation of trials in multi-environments over several years.

Results regarding the efficiency of AF models have also been reported for other crops. Resende and Thompson (2004) aimed to show the superiority of the AF model with heterogeneous residual variances in relation to the AMMI for the eucalyptus crop and observed

Genetics and Molecular Research 16 (2): gmr16029672 
that the heterogeneity among the variances in specific environments provided estimates of the complete correlation structure, facilitating practical decisions to be made in the context of the study of the GxE interaction. Stefanova and Buirchell (2010) also observed that the AF approach provides a representation of a parsimonious structure of genetic variation, and also provides a clear interpretation of the adaptability and stability of the genotypes evaluated in multi-environment trials.

In light of the preceding, evaluation and identification of maize hybrids that have high GY in environments with and without water restriction are fundamental for a continual increase in grain production, allowing greater yield stability to be attained. These considerations are even more relevant when considering the current scenario of maize production in Brazil, with an increasing trend of expansion of planted area in the second crop season (safrinha), in which the risks associated with water deficit are greater. Besides, this has been the direction adopted in the main maize production regions of the world, where climate adversities have been more and more frequent, and maize hybrids that have tolerance to water deficit have been preferred since they associate good yield under environments with water restriction and a good response to more favorable environmental conditions. For that reason, the use of tools in the analysis for evaluation of the GxE interaction, such as the AF methodology, is essential, allowing identification of superior cultivars with genetic stability for the characteristics of interest.

In conclusion, the hybrids G66, G99, G86, and G26 are the most stable and show potential for use in environments with and without water restriction.

The AF models are useful for evaluation of hybrids over several years because they allow selection of the best hybrids with adaptability and specific and wide stability and reveal the hybrids with good characteristics for grain production, as well as identification of megaenvironments with greater correlation among themselves.

\section{Conflicts of interest}

The authors declare no conflict of interest.

\section{ACKNOWLEDGMENTS}

The authors thank Coordenação de Aperfeiçoamento de Pessoal de Nível Superior (CAPES), Embrapa Milho e Sorgo, and Conselho Nacional de Desenvolvimento Científico e Tecnológico $(\mathrm{CNPq})$ for their support in carrying out this study.

\section{REFERENCES}

Albuquerque PEP, Gomide RL, Andrade CLT, Viana JHM, et al. (2006). Caracterização climática do sítio-específico de Janaúba para a fenotipagem de cereais visando estudos de tolerância à seca. Embrapa Milho e Sorgo, Brasília.

Assefa Y, Roozeboom KL, Staggenborg AS and Du J (2012). Dryland and irrigated maize yields with climate, management, and hybrid changes from 1939 through 2009. Agron. J. 104: 473-482. https://doi.org/10.2134/agronj2011.0242

Bai LP, Sui FG, Ge TD, Sun ZH, et al. (2006). Effect of soil drought stress on leaf water status, membrane permeability and enzymatic antioxidant system of maize. Pedosphere 16: 326-332. https://doi.org/10.1016/S1002-0160(06)60059-3

Bänziger M, Edmeades GO, Beck D and Bellon M (2000). Breeding for drought and nitrogen stress tolerance in maize: from theory to practice. CIMMYT, México.

Campos H, Cooper M, Edmeades GO, Loffler C, et al. (2006). Changes in drought tolerance in maize associated with fifty years of breeding for yield in the U.S. Maize belt. Maydica 51: 369-381.

Genetics and Molecular Research 16 (2): gmr16029672 
Chapman SC, Crossa J, Basford KE and Kroonenberg PM (1997). Genotype by environments effects and selection for drought tolerance in tropical maize. I. Two mode pattern analysis of yield. Euphytica 95: 1-9. https://doi. org/10.1023/A:1002918008679

Chen J, Xu W, Velten J, Xin Z, et al. (2012). Characterization of maize inbred lines for drought and heat tolerance. J. Soil Water Conserv. 67: 354-364. https://doi.org/10.2489/jswc.67.5.354

Chenu K, Chapman SC, Tardieu F, McLean G, et al. (2009). Simulating the yield impacts of organ-level quantitative trait loci associated with drought response in maize: a "gene-to-phenotype" modeling approach. Genetics 183: 15071523. https://doi.org/10.1534/genetics.109.105429

Cooper M, Gho C, Leafgren R, Tang T, et al. (2014). Breeding drought-tolerant maize hybrids for the US corn-belt: discovery to product. J. Exp. Bot. 65: 6191-6204. https://doi.org/10.1093/jxb/eru064

Edmeades GO, Chapman SC and Lafitte HR (1999). Selection improves drought tolerance in tropical maize populations: I. Gains in biomass, grain yield, harvest index. Crop Sci. 39: 1306-1315. https://doi.org/10.2135/cropsci1999.3951306x

Figueiredo AG, VonPinho RG, Silva HD and Balestre M (2014). Application of mixed models for evaluating stability and adaptability of maize using unbalanced data. Euphytica 202: 1-17.

Hao Z, Li X, Xie C, Weng J, et al. (2011). Identification of functional genetic variations underlying drought tolerance in maize using SNP markers. J. Integr. Plant Biol. 53: 641-652. https://doi.org/10.1111/j.1744-7909.2011.01051.x

Lafitte R, Blum A and Atlin G (2003). Using secondary traits to help identify drought-tolerant genotypes. Crop Sci. 32: 234-246.

Lopes MS, Araus JL, van Heerden PD and Foyer CH (2011). Enhancing drought tolerance in C(4) crops. J. Exp. Bot. 62: 3135-3153. https://doi.org/10.1093/jxb/err105

Nuvunga JJ, Oliveira LA, Pamplona AKA, Silva CP, et al. (2015). Factor analysis using mixed models of multi-environment trials with different levels of unbalancing. Genet. Mol. Res. 14: 14262-14278. https://doi.org/10.4238/2015. November. 13.10

Patterson HD and Thompson R (1971). Recovery of inter-block information when block sizes are unequal. Biometrika 58: 545-554. https://doi.org/10.1093/biomet/58.3.545

Peixouto LS, Nunes JAR and Furtado DF (2016). Factor analysis applied to the G+ GE matrix via REML/BLUP for multienvironment data. Crop Breed. Appl. Biotechnol. 16: 1-6. https://doi.org/10.1590/1984-70332016v16n1a1

Piepho HR (1998). Empirical best linear unbiased prediction in cultivar trials using factor-analytic variance-covariance structures. Theor. Appl. Genet. 97: 195-201. https://doi.org/10.1007/s001220050885

R Core Team (2013). R: a language and environment for statistical computing. Vienna: R Foundation for Statistical Computing, 2013. Available at [http://www.R-project.org/]. Accessed May 12, 2015.

Resende MDV and Thompson R (2004). Factor analytic mixed models in the analysis of multiple experiments. Rev. Mat. Estat. 22: 1-22.

Resende MDV and Duarte JB (2007). Precisão e controle de qualidade em experimentos de avaliação de cultivares. Pesqui. Agropecu. Trop. 37: 182-194.

Smith AB, Cullis BR and Gilmour A (2001). The analysis of crop variety evaluation data in Australia. Aust. N. Z. J. Stat. 43: 129-145. https://doi.org/10.1111/1467-842X.00163

Smith AB, Ganesalingam A, Kuchel H and Cullis BR (2015). Factor analytic mixed models for the provision of grower information from national crop variety testing programs. Theor. Appl. Genet. 128: 55-72. https://doi.org/10.1007/ $\underline{\text { s00122-014-2412-x }}$

Stefanova KT and Buirchell B (2010). Multiplicative mixed models for genetic gain assessment in lupin breeding. Crop Sci. 50: 880-891. https://doi.org/10.2135/cropsci2009.07.0402

\section{Supplementary material}

Table S1. Code (Code) and hybrid (Hyb.) of the 171 hybrids evaluated, UFLA, Lavras, MG, Brazil, 2016. 